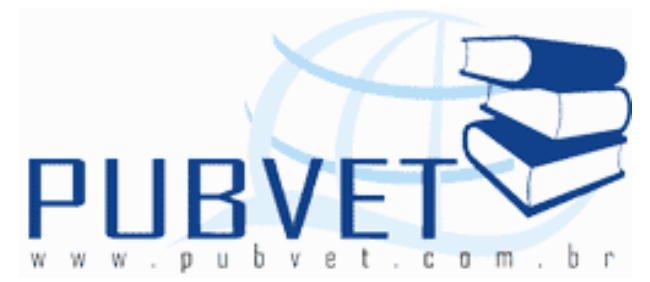

PUBVET, Publicações em Medicina Veterinária e Zootecnia.

\title{
Produção de forrageiras hidropônicas de triticales com ervilhaca comum
}

Osmar Souza dos Santos ${ }^{1}$, Alfredo do Nascimento Junior ${ }^{2}$, Denise Puntel Basso $^{3}$, Alberto Cargnelutti Filho ${ }^{4}$, Jorge Eugênio Filipetto ${ }^{5}$, Rodrigo da Costa Luz $^{6}$, Vanderson Rocha ${ }^{7}$

${ }^{1}$ Engenheiro Agrônomo, Doutor, Professor Colaborador do Colégio Politécnico da Universidade Federal de Santa Maria (UFSM). Pesquisador do CNPq. 97105900, Santa Maria, RS. osmarsouzasantos@gmail.com

2 Engenheiro Agrônomo, Doutor, Pesquisador da Embrapa-Trigo. 99001-970, Passo Fundo, RS. alfredo@cnpt.embrapa.br

${ }^{3}$ Engenheira Agrônoma da UFSM. denisepbasso@gmail.com

${ }^{4}$ Engenheiro Agrônomo, Doutor, Professor do Departamento de Fitotecnia da UFSM. cargnelutti@ufrgs.br

${ }^{5}$ Técnico do Colégio Politécnico da UFSM. jorgefilipetto@gmail.com

${ }^{6}$ Acadêmico da UFSM. rodrigodacostaluz@yahoo.com.br

7 Aluno do Colégio Politécnico da UFSM. sqrocha@hotmail.com

\section{Resumo}

Foi realizado um experimento no Colégio Politécnico da Universidade Federal de Santa Maria (UFSM) - RS, com objetivo de avaliar a produção de forrageiras hidropônicas de três variedades de triticale (X Triticosecale Wittmack): BRS Saturno, BRS Ulisses e Embrapa 53, nas densidades de 2,0 kg 
$\mathrm{m}^{-2}$, associadas com quatro densidades de ervilhaca comum denominada SS Ametista (Vicia sativa L.) nas doses de $0,150,300$ e $450 \mathrm{~g} \mathrm{~m}^{-2}$, no período do inverno de 2011. O experimento foi conduzido em túnel alto com cada tratamento em área de $1,0 \mathrm{~m}^{-2}$, utilizando-se solução nutritiva descrita por Santos et al. (2004). As avaliações foram realizadas aos 17 dias após a semeadura. As variedades BRS Ulisses e Embrapa 53 apresentaram as maiores produtividades médias, 19,867 e $19,328 \mathrm{~kg} \mathrm{~m}^{-2}$, porém a máxima foi 22,313 $\mathrm{kg} \mathrm{m}^{-2}$ produzida pela BRS Ulisses associada com $300 \mathrm{~g} \mathrm{~m}^{-2}$ de ervilhaca comum o que indica o sucesso do uso dessa ervilhaca.

Palavras-chave: hidroponia, forrageiras, triticales, ervilhaca.

\section{Production of hydroponic fodder of triticale with common vetch}

\section{Abstract}

An experiment was conducted at the Colégio Politécnico da Universidade Federal de Santa Maria (UFSM) - RS, in order to evaluate the production of hydroponic fodder of three varieties of triticale (X Triticosecale Wittmack): BRS Saturno, BRS Ulisses and Embrapa 53 at the densities $2.0 \mathrm{~kg} \mathrm{~m}^{-2}$, associated with four densities of common vetch named SS Ametista (Vicia sativa L.) at doses of $0,150,300$ and $450 \mathrm{~g} \mathrm{~m}^{-2}$, during the winter of 2011 . The experiment was conducted in a high tunnel with each treatment in an area of $1.0 \mathrm{~m}^{-2}$, using a nutrient solution described by Santos et al. (2004). Evaluations were performed at 17 days after sowing. Varieties BRS Ulisses and Embrapa 53 had the highest average yield with 19.867 and $19.328 \mathrm{~kg} \mathrm{~m}^{-2}$, but the maximum productivity was $22.313 \mathrm{~kg} \mathrm{~m}^{-2}$ yielded by BRS Ulisses associated with $300 \mathrm{~g}$ $\mathrm{m}^{-2}$ of Smooth Vetch, which indicates the success the use of this vetch.

Keywords: hydroponics, forage, triticales, common vetch, SS Ametista. 
SANTOS, O.S. et al. Produção de forrageiras hidropônicas de triticales com ervilhaca comum. PUBVET, Londrina, V. 5, N. 38, Ed. 185, Art. 1248, 2011.

\section{INTRODUÇÃO}

A deficiência de pastagens de boa qualidade ocorre no sul do Brasil, tanto no inverno, devido as baixas temperaturas, geadas e excessos de chuvas, como no verão devido a falta de chuvas adequadas.

O cultivo de forragem hidropônica é uma tecnologia de produção de biomassa vegetal obtida através da germinação e desenvolvimento inicial das plantas a partir de sementes viáveis, de alta digestibilidade e qualidade nutricional (FAO, 2001).

A produção de forragem hidropônica tem como vantagens a eliminação do uso de defensivos agrícolas, uma vez que não ocorrem invasoras prejudiciais, doenças e pragas no sistema, ciclo de produção mais rápido, independência das mudanças nas condições climáticas ao longo do ano, maior produtividade por unidade de área, redução da mão de obra, redução das tarefas inerentes à produção e conservação de forragens (silagem, fenação), economia e melhor aproveitamento dos fertilizantes, liberação de área para uso com outras culturas e uso de diferentes espécies vegetais (SANTOS et al., 2002).

A utilização de forragem hidropônica de alta qualidade, obtida em condições de ambientes protegidos, permite ao produtor manter e aumentar a produtividade de seus rebanhos independente das variações climáticas, resultando em maior estabilidade da produção.

Entre as várias espécies vegetais que podem ser utilizadas para produção de forragens hidropônicas cabe destaque para variedades de Triticale, que vêm sendo pesquisadas (SANTOS et al., 2010).

O triticale é cereal abundantemente encontrado no sul do Brasil, tem na alimentação animal sua principal utilização, com o uso de grãos na forma de ração para suínos e aves (NASCIMENTO JUNIOR et al., 2004).

Esta pesquisa teve como objetivo avaliar a produção de três cultivares de Triticale em hidroponia associados com quatro densidades de Ervilhaca Comum. 
SANTOS, O.S. et al. Produção de forrageiras hidropônicas de triticales com ervilhaca comum. PUBVET, Londrina, V. 5, N. 38, Ed. 185, Art. 1248, 2011.

\section{MATERIAL E MÉTODOS}

O experimento foi realizado no Colégio Politécnico da Universidade Federal de Santa Maria - RS, com coordenadas geográficas: latitude 29042'S, longitude 53043'W e altitude $95 \mathrm{~m}$.

As variedades foram conduzidas em um túnel alto com $6 \mathrm{~m}$ de largura e $30 \mathrm{~m}$ de comprimento, disposto no sentido norte-sul, coberto com polietileno de baixa densidade (PEBD) com espessura de $150 \mu$, aditivado contra raio ultravioleta. Os canteiros foram confeccionados com filme plástico (lona preta de $100 \mu$ de espessura), estendidos sobre o solo nivelado, sendo as bordas limitadas por guias de madeira com $6,0 \mathrm{~cm}$ de altura, formando parcelas de $1,0 \mathrm{~m}^{2}$.

O experimento foi realizado no período de 17 dias, de 22 de julho a 8 de agosto de 2011, com três cultivares de Triticale (X Triticosecale Wittmack): BRS Saturno, BRS Ulisses e Embrapa 53, na densidade de 2,0 $\mathrm{kg} \mathrm{m}^{-2}$, associadas com ervilhaca comum SS Ametista (Vicia sativa L.) nas doses de 0 , 150,300 e $450 \mathrm{~g} \mathrm{~m}^{-2}$.

Antes da semeadura, foi realizada a técnica de pré-germinação que consistiu na embebição das sementes em água por 24 horas (SANTOS et al., 2006). Logo após, foram semeadas de acordo com cada tratamento.

As plantas receberam solução nutritiva desenvolvida especialmente para produção de forrageiras (SANTOS et al., 2004).

Aos 17 dias da semeadura (Figuras 1 e 2) foi feita a coleta e pesagem de quatro amostras de $0,20 \times 0,20 \mathrm{~m}$ de todos os tratamentos.

\section{RESULTADOS E DISCUSSÃO}

Os resultados obtidos nas pesagens, em $\mathrm{g} \mathrm{m}^{-2}$, foram transformados em $\mathrm{kg} \mathrm{m}^{-2}$ e $\mathrm{kg} \mathrm{ha}^{-1}$, que se encontram na Tabela 1.

A quantidade média ( $300 \mathrm{~g} \mathrm{~m}^{-2}$ ) de sementes de ervilhaca comum usada nessa pesquisa representa um valor 50 vezes maior do que a quantidade utilizada na semeadura em solos, equivalente a $60 \mathrm{~kg} \mathrm{ha}^{-1}$ (FONTANELI et al., 
SANTOS, O.S. et al. Produção de forrageiras hidropônicas de triticales com ervilhaca comum. PUBVET, Londrina, V. 5, N. 38, Ed. 185, Art. 1248, 2011.

2009), porém essa quantidade maior é indispensável para a produção conjunta com triticales (Figura 2).

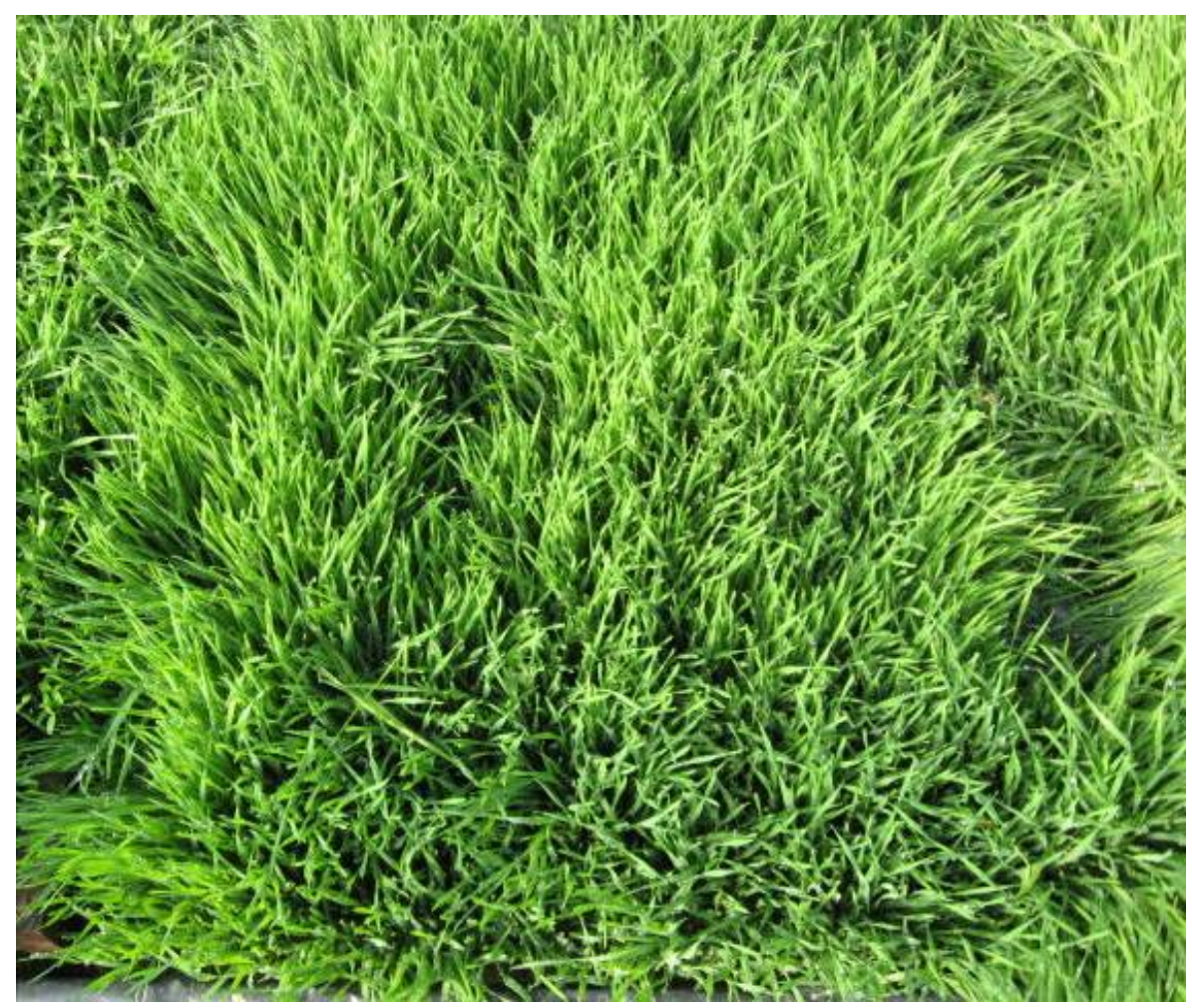

Figura 1. Produção de triticale sem ervilhaca.

A maior produção, na média, foi da cultivar BRS Ulisses com 19,867 kg $\mathrm{m}^{-2}$, equivalente a $199 \mathrm{t} \mathrm{ha}^{-1}$, seguida pela Embrapa 53, com 19,328 $\mathrm{kg} \mathrm{m}^{-2}$, equivalente a $193 \mathrm{t} \mathrm{ha}^{-1}$, e tendo como última a BRS Saturno com 13,625 kg $\mathrm{m}^{-2}$, equivalente a $136 \mathrm{t} \mathrm{ha}^{-1}$ (Figura 3 ). Verifica-se que houve grande aumento na produção de forrageiras em comparação com outra pesquisa onde os valores foram $62,5 \mathrm{t} \mathrm{ha}^{-1}$ com a BRS Minotauro, 62,4 $\mathrm{t} \mathrm{ha}^{-1}$ com a BRS Ulisses e 77,2 t ha $^{-1}$ com a Embrapa 53 (SANTOS et al., 2011), tendo como justificativa para esse aumento a ampliação de 15 para 17 dias após a semeadura e a melhor qualidade das sementes. 


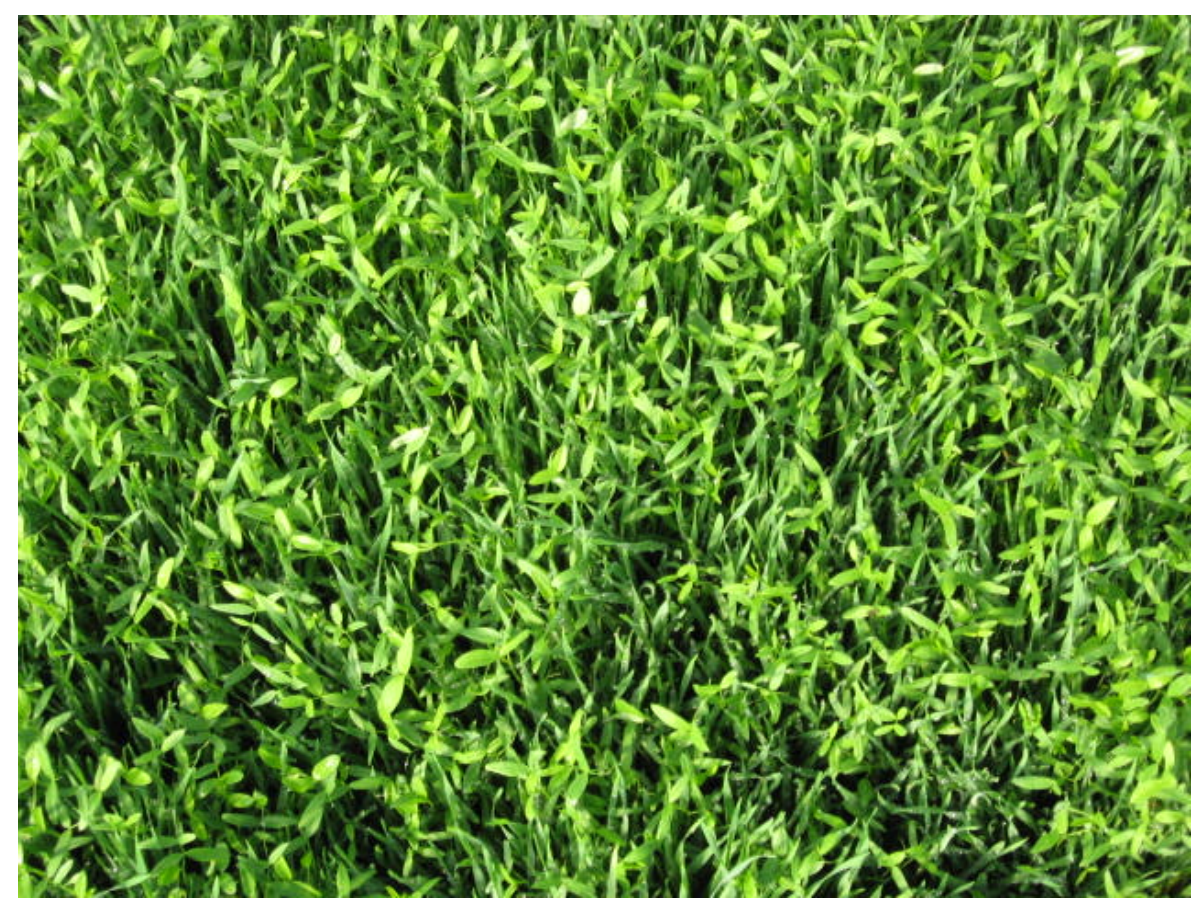

Figura 2. Produção de triticale com ervilhaca comum SS Ametista.

Os valores citados representam ótima produção em comparação com a produção hidropônica do centeio, $9,8 \mathrm{~kg} \mathrm{~m}^{-2}$, e da cevada, 9,1 $\mathrm{kg} \mathrm{m}^{-2}$, ambos colhidos aos 14 dias após a semeadura e muito bem adaptados ao sistema de produção de forrageiras, sendo que as forragens hidropônicas de cevada e de centeio consorciadas com ervilhaca comum são alternativas que possibilitam a produção de alimentos volumosos com bom valor nutricional (SANTOS et al., 2009).

Os resultados obtidos destacaram, em média, como mais produtivas a BRS Ulisses e a Embrapa 53, que também foram as mais eficientes em pesquisa anterior (SANTOS et al., 2011), ficando em último lugar a BRS Saturno, porém com produção muito eficiente (Figura 3). 
SANTOS, O.S. et al. Produção de forrageiras hidropônicas de triticales com ervilhaca comum.

PUBVET, Londrina, V. 5, N. 38, Ed. 185, Art. 1248, 2011.

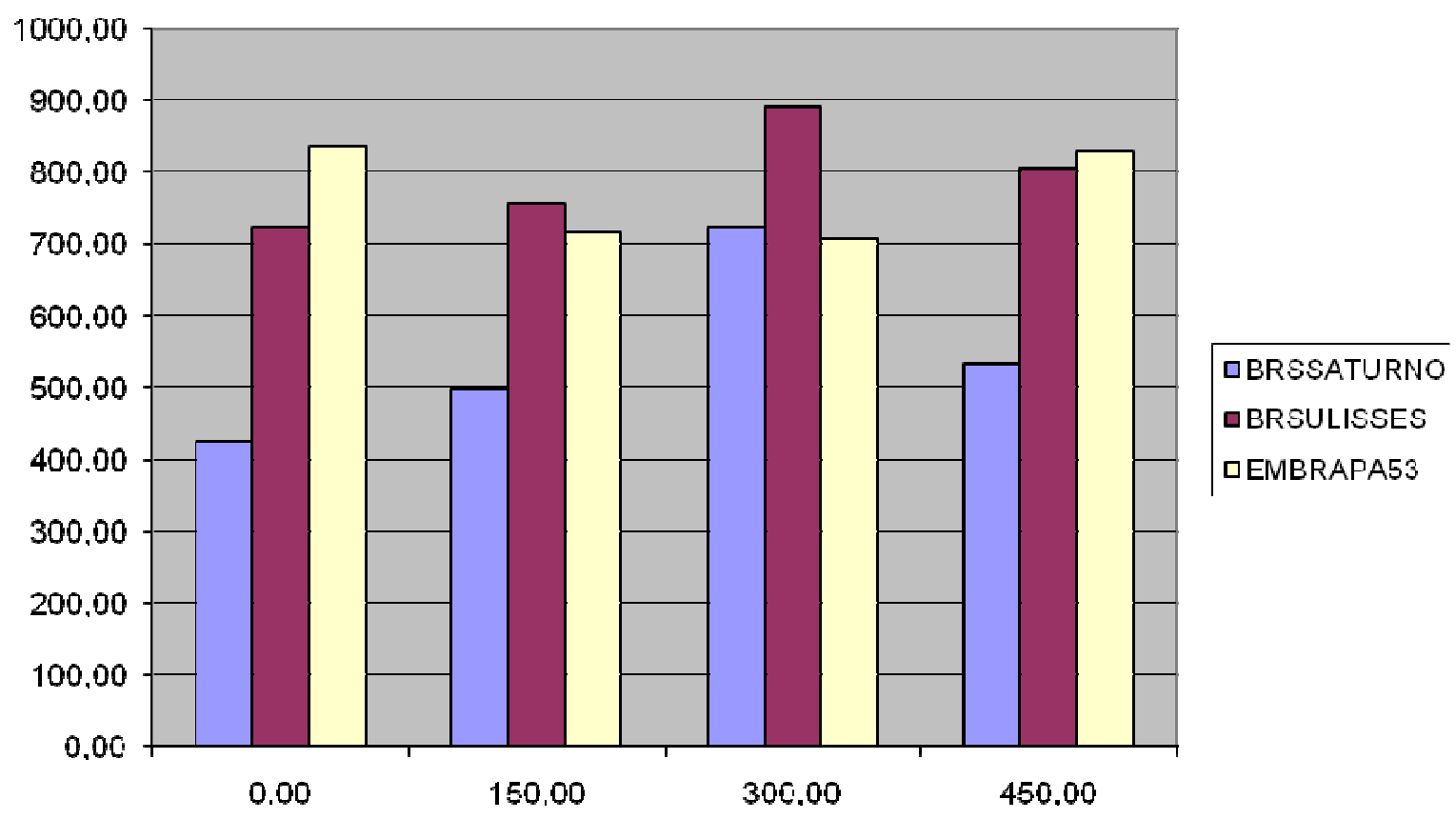

Figura 3. Produção das três forrageiras de triticales $\left(2 \mathrm{~kg} \mathrm{~m}^{-2}\right)$ sem e com ervilhaca comum $\left(0,150,300\right.$ e $\left.450 \mathrm{~g} \mathrm{~m}^{-2}\right)$.

Cabe destacar que a maior produção foi obtida pela BRS Ulisses associada com $300 \mathrm{~g} \mathrm{~m}^{-2}$ da ervilhaca comum, atingindo $22,313 \mathrm{~kg} \mathrm{~m}^{-2}$, equivalente a $223 \mathrm{t} \mathrm{ha}^{-1}$, seguida da Embrapa 53 que apresentou sua maior produção sem ervilhaca, atingindo $20,906 \mathrm{~kg} \mathrm{~m}^{-2}$, equivalente a $209 \mathrm{t} \mathrm{ha}^{-1}$, e como última BRS Saturno que associada a $300 \mathrm{~g} \mathrm{~m}^{-2}$ de ervilhaca comum, atingiu $18,094 \mathrm{~kg} \mathrm{~m}^{-2}$, equivalente a $181 \mathrm{t} \mathrm{ha}^{-1}$.

\section{CONCLUSÕES}

A cultivar de triticale BRS Ulisses, com $2 \mathrm{~kg} \mathrm{~m}^{-2}$, associada à ervilhaca comum, com $300 \mathrm{~g} \mathrm{~m}^{-2}$, é mais produtiva, seguida da Embrapa 53 e da BRS Saturno.

A dose mais eficiente de ervilhaca comum é a de $300 \mathrm{~g} \mathrm{~m}^{-2}$ para ser associada com cultivares de Triticale. 


\section{REFERÊNCIAS BIBLIOGRÁFICAS}

FAO. Manual técnico forraje verde hidropônico. Santiago, 2001. v.1, 73p.

FONTANELI, R.S.; SANTOS, H.P.; BAIER, A.C. Leguminosas anuais de inverno. In: FONTANELI, R.S. et al. Forrageiras para integração lavoura-pecuária-floresta na região SulBrasileira. Passo Fundo: Embrapa, 2009, p.247-262.

NASCIMENTO JUNIOR, A.; BAIER, A.C.; TEIXEIRA, M.C.C.; WIETHÖLTER, S. Triticale in Brazil. In: Mohamed Mergoum; Helena Gómez MacPherson. (Org.). Triticale Improvement And Production. 1 ed. Roma: FAO, 2004, v.1, p.93-98.

SANTOS, O.S.; MANFRON, P.A.; MÜLLER, L.; MEDEIROS, S.L.P.; TONETTO, C.J.; BANDEIRA, A.H.; DUARTE, T.S.; LUZ, G.L.; BORCIONI, E. Produção e qualidade nutricional da forragem hidropônica. Informe Técnico. Santa Maria: UFSM/CCR, 2006, 8p. (34/2006).

SANTOS, O.S.; NASCIMENTO JUNIOR, A.; NOGUEIRA FILHO, H.; FRONZA, D.; BASSO, D.P.; LUZ, R.C. Produção de forrageiras hidropônicas de triticales. PUBVET, Londrina, v.5, n.14, ed. 161, art. 1090, 2011. 8p.

SANTOS, O.S.; MÜLLER, L.; PIRES, C.; TONETTO, C.J.; MEDEIROS, S.L.P.; FRESCURA, R.B.N. ; HAUT, V.; SILVA, D.V.R. Produção de forragem hidropônica de cevada e milho e seu uso na alimentação de cordeiros. Informe Técnico. Santa Maria: UFSM/CCR, 2004, 8p. (04/2004).

SANTOS, O.S.; NASCIMENTO JUNIOR, A.; FRONZA, D.; NOGUEIRA FILHO, H. et al. Produção de forrageiras hidropônicas de três espécies de poáceas, no inverno. PUBVET, Londrina, v.4, n.16, ed. 121, art. 821, 2010.

SANTOS, O.S.; SCHMIDT, D.; NOGUEIRA FILHO, H.; LONDERO, F.A. Produção de forragem hidropônica. In:__. Cultivos sem solo: hidroponia. 2a. Reimpressão. Santa Maria: UFSM/CCR, 2002. p.94-98. (Caderno Didático, 01).

SANTOS, O.S.; ZORZAN, M.H.S.; NOGUEIRA FILHO, H.; FRONZA, D.; DURANTE, E.C. Qualidade de forragens hidropônicas de centeio, cevada e ervilhaca. PUBVET, Londrina, v.3, n. 16, Art n. 571, 10p. Mai 1, 2009. 